\title{
DOAÇÃO COMPARTILHADA DE OÓCITOS NO BRASIL: REFLEXÃO BIOÉTICA À LUZ DO CONCEITO DE VULNERABILIDADE E DOS DIREITOS HUMANOS DOS PACIENTES
}

EGG-SHARING DONATION IN BRAZIL: BIOETHICAL REFLECTION IN LIGHT OF THE CONCEPT OF VULNERABILITY AND THE HUMAN RIGHTS OF PATIENTS

Kalline Carvalho Gonçalves Eler Aline Albuquerque Sant'Anna de Oliveira

\section{RESUMO}

Este estudo objetiva analisar a doação compartilhada de oócitos, autorizada pela Resolução no 2.121/2015 do CFM. Adotou-se o referencial dos Direitos Humanos dos Pacientes, especificamente o direito à privacidade e à informação, considerando as vulnerabilidades vivenciadas pela paciente. Trata-se de pesquisa teórico-normativa, tendo sido comparados o modelo brasileiro normativo de reprodução assistida com os modelos propostos pela REDLARA e pela Autoridade de Fertilização Humana e Embriologia do Reino Unido. Concluiu-se que o reconhecimento das vulnerabilidades não inviabiliza o exercício da autonomia, mas é necessária edição de uma lei diante da insuficiência da resolução para proteger a paciente.

Palavras-Chave: Doação de oócitos. Direitos Humanos. Consentimento informado. 


\section{ABSTRACT}

This paper aims to analyze the egg-sharing donation authorized by the Resolution 2.121/2015 of Brazilian Federal Council of Medicine in the view of vulnerability and Human Rights of Patients, specifically the right to privacy and information. It is a theoretical-normative research. The brazilian normative model of assisted reproduction was compared with the models proposed by REDLARA and the Human Fertilization and Embryology Authority of the United Kingdom. It was concluded that the recognition of vulnerabilities does not impair the exercise of autonomy, but it is necessary a law to protect the patient.

Key-Words: Oocyte donation. Human Rights. Informed consent.

\section{INTRODUÇÃO}

Do emprego das técnicas de reprodução assistida (RA) emerge uma série inédita de questões ético-jurídicas relacionadas à fecundação in vitro. Destaca-se, nesse contexto, a doação de oócitos (células germinais femininas) que, segundo o último relatório da Rede Latino-americana de Reprodução Assistida (REDLARA), publicado em 2016, no Brasil, representa 1.159 casos verificados nas clínicas de RA.

O problema da escassez de bancos de oócitos, em razão da complexidade da técnica de retirada e implantação das células germinais femininas e dos riscos envolvidos na coleta, levou o Conselho Federal de Medicina - CFM a autorizar, desde 2013, a chamada doação compartilhada de oócitos na qual doadora e receptora, participando como portadoras de problemas de reprodução, podem compartilhar o material biológico e os custos financeiros que envolvem o procedimento de RA.

Atualmente, a prática da RA e da doação de oócitos encontram-se regulamentadas pela Resolução no 2.121/2015 do CFM, a única norma no país sobre RA. Sendo assim, no Brasil, não há lei que disponha sobre o tema, o que revela um atraso, porquanto a matéria, além de ultrapassar o âmbito do exercício profissional da medicina, envolve questões éticas, de direitos dos envolvidos no uso das técnicas de RA, de manipulação genética, biossegurança e segurança do paciente. Consequentemente, é evidente que matéria de tamanha complexidade e relevância deve ser 
disciplinada por lei, como os exemplos da Argentina, Espanha, Itália, Reino Unido, Alemanha, Áustria e Suécia, países que contam com leis específicas sobre RA.

A doação de oócitos instiga debates acerca da sua eticidade e adequação às normas de direitos humanos, notadamente em razão de poder ser utilizada para ocultar a comercialização de gametas no Brasil. Com efeito, tendo em vista que o Sistema Único de Saúde - SUS não aloca recursos suficientes para atender às demandas relacionadas às técnicas de RA e que muitas mulheres acabam envelhecendo durante a espera, diminuindo as chances de gravidez, a doação compartilhada de oócitos apresenta-se, para algumas mulheres, como uma alternativa para levar a cabo a gravidez almejada. Através da doação dos seus oócitos, essas mulheres, pacientes do SUS, recebem como contrapartida o custeio do tratamento de infertilidade pela receptora.

Considerando o quadro apontado concernente ao risco concreto de comercialização de oócitos no país, este estudo objetiva analisar a prática da doação compartilhada à luz do conceito de vulnerabilidade e do referencial teórico-normativo dos Direitos Humanos dos Pacientes (ALBUQUERQUE, 2016), especificamente do direito à privacidade e à informação. Escolheu-se tal referencial em razão de seu ineditismo no Brasil e de propiciar ferramenta teórico-prática para a reflexão e prescrição de temas bioéticos e jurídicos. Sendo assim, os Direitos Humanos dos Pacientes, enquanto ramo do Direito Internacional dos Direitos Humanos, são aqueles direitos previstos em documentos internacionais que incidem nos cuidados em saúde, e cujo arcabouço teórico é conformado pelos princípios da dignidade humana, da autonomia relacional, do cuidado centrado no paciente e da responsabilidade.

Os Direitos Humanos dos Pacientes abarcam uma série de direitos, tais como o direito à vida, o direito à privacidade e o direito à informação, dentre outros. Ademais, registre-se que tal referencial se aparta da lógica do direito consumerista, que permeia o Direito do Consumidor, e se fundamenta na lógica do cuidado.

Considerando o recorte realizado neste artigo, optou-se por empregar a concepção de vulnerabilidade, conceito nuclear dos Direitos Humanos dos Pacientes, e os direitos à privacidade e à informação da paciente envolvida 
no processo de RA. Ainda, tendo em conta o desenho metodológico adotado, buscou-se examinar a prática da doação compartilhada tão somente sob a perspectiva da doadora, considerando que caso haja a venda, mesmo que indireta de oócitos, é essa que se submete, por questões financeiras ou de falta de acesso a serviços de saúde, à venda. Logo, nota-se que a doadora, no contexto da problemática abordada neste artigo, tem sua vulnerabilidade acrescida na medida em que se submete a riscos específicos no processo de estimulação ovariana e não se beneficia diretamente desse procedimento.

Trata-se de pesquisa teórica cujo escopo é aprofundar a discussão sobre o tema objeto de análise, de modo a proporcionar um espaço de reflexão com o intuito de contribuir para a formulação de marcos normativos sobre RA no Brasil. Para tanto, o presente artigo se encontra estruturado em três partes. Inicialmente, apresenta-se um panorama do contexto brasileiro da doação compartilhada de oócitos. Em um segundo momento, a fim de verificar de problematizar a incidência dos direitos à privacidade e à informação da doadora de oócitos no Brasil, realizou-se uma comparação do modelo brasileiro normativo de RA com os modelos propostos pela REDLARA e pela Autoridade de Fertilização Humana e Embriologia do Reino Unido. Optou-se pela REDLARA por ser a instituição científica e educacional que agrupa mais de 90\% dos centros de RA da América Latina, sendo que dos 160 estabelecimentos brasileiros estimados pela Agência Nacional de Vigilância Sanitária (ANVISA, 2017), 65 estão acreditados pela REDLARA. Essa instituição em 2011 apresentou uma série de vinte e três "Formulários de Educação e Consentimentos em Reprodução Assistida", tendo sido analisado aqui apenas o formulário da doação de oócitos. Em relação ao modelo britânico de RA, a escolha justifica-se por se tratar de uma região que desde 1990 conta com uma lei específica sobre o tema - The Human Fertilisation and Embryology Act, revista em 2003 e 2008, e desde 1998 regulamenta a prática da doação compartilhada. Além da Lei que regula de forma abrangente a matéria, todos os procedimentos referentes à RA no Reino Unido encontram-se pormenorizadamente regulamentados em um Código de Prática cuja oitava edição foi publicada em 2016 e serve de referência para pacientes, doadores, pesquisadores e aqueles que trabalham no setor de fertilidade. No Código citado há 
um total de 33 notas de orientação sobre a temática que devem ser rigorosamente seguidas por todas as clínicas de fertilização, sob pena de perderem o registro. As notas de orientação encontram-se divididas em quatro seções: requisitos obrigatórios, interpretação da HFEA dos requisitos obrigatórios, diretrizes da HFEA e outras legislações, diretrizes profissionais e informação. Neste trabalho, foram examinadas apenas as notas que abordam a temática da doação de oócitos e os conteúdos dos direitos à privacidade e à informação, a saber Nota 3. Aconselhamento, Nota 4. Informação a ser providenciada antes do consentimento, Nota 5. Consentimento para tratamento, armazenamento, doação e divulgação da informação e Nota 12. Ajustes para doação de óvulos.

Em seguida, passa-se à abordagem da doação de oócitos em âmbito nacional.

\section{A DOAÇÃO DE OÓCITOS NO CONTEXTO BRASILEIRO}

A doação de gametas encontra-se regulada pela Resolução 2.121/15, editada pelo CFM, que proíbe seu caráter lucrativo ou comercial; determina que os doadores não conheçam a identidade dos receptores e vice-versa e coloca como sendo responsabilidade do médico assistente a escolha do doador para garantir maior semelhança fenotípica e máxima possibilidade de compatibilidade (BRASIL, 2015).

Para que haja a doação de oócitos, primeiramente, é necessária a administração de uma alta dosagem de hormônios visando aumentar a produção de folículos que, em um segundo momento, serão aspirados por meio de cirurgia. Tendo em vista a complexidade do procedimento, o instituto de Ensino e Pesquisa em Medicina Reprodutiva de São Paulo publicou, em 2014, estudo no qual os autores concluíram que as pacientes previamente submetidas a tratamentos de infertilidade mal sucedidos estariam mais abertas à ovodoação, independentemente da idade ou escolaridade. Constatou-se também que pacientes que ainda não tinham realizado nenhuma tentativa não consideravam a doação ou recebimento como uma opção (PARAMES et al., 2014). 
Diante do fato do procedimento de doação ser excessivamente invasivo, pode-se supor que, dificilmente, alguém fora do contexto de tratamento da RA estaria disposto a sofrer tantas interferências por questões puramente altruístas e, provavelmente, devido a tal fator, conjugado com outros estranhos ao tema desta pesquisa, a formação de um banco de oócitos no Brasil não obteve êxito.

Em resposta ao problema da escassez de oócito, a resolução do CFM prevê a situação identificada como doação compartilhada de oócitos em que doadora e receptora, participando como portadoras de problemas de reprodução, compartilham tanto do material biológico quanto dos custos financeiros que envolvem o procedimento de RA, tendo a doadora preferência sobre o material biológico que será produzido. A modalidade é empregada quando existem mulheres férteis do ponto de vista hormonal e de seus ovários, que podem doar seus oócitos para outras mulheres, em geral mais velhas, com baixa fertilidade (CORREAA; LOYOLA, 2015) (CORRÊA, 2000) (SANDI, 2012).

O debate bioético atual como demonstra Côrrea (CORRÊA; LOYOLA, 2015) apresenta uma preferência pela doação compartilhada em detrimento da simples doação, pois, no primeiro caso, há um modelo de reciprocidade baseado no ajustamento de necessidades em que a doadora deseja também reproduzir e os riscos a que será submetida já estão incluídos no tratamento. A doação remunerada, por sua vez, tem sido rechaçada, pois os riscos seriam assumidos simplesmente por um interesse econômico, sem qualquer relação com a reprodução ou tratamento da doadora. Entende-se, nesse caso, que haveria uma mercantilização do gameta humano (LEVINE, 2010).

A doação compartilhada de oócitos encontra um terreno fértil para se firmar como meio de se ampliar o uso das novas tecnologias reprodutivas (SANDI, 2012) visto que constitui em alternativa para mulheres que não podem custear o tratamento e que seriam obrigadas a esperar por anos pelo serviço público. Por outro lado, traz consigo indagações bioéticas acerca da autonomia da decisão tomada em um contexto de vulnerabilidades, principalmente socioeconômica (CORRÊA; LOYOLA, 2015) (CORRÊA, 2000). 
Alguns estudiosos do tema no Brasil sustentam a ilegalidade na doação compartilhada por se tratar de uma comercialização velada de óvulos. No Reino Unido, preocupações semelhantes acerca da mercantilização dos gametas e do consentimento informado também foram levantadas por vários setores da sociedade. No entanto, após mais de 15 anos de regularização da prática, um estudo empírico inédito que verificou a avaliação das doadoras sobre o consentimento e a validade de suas decisões, constatou que $91,7 \%$ das pacientes estavam satisfeitas com o processo de tomada de decisão e $83,3 \%$ o fariam de novo se fosse necessário (GÜRTIN; AHUJA; GOLOMBOK, 2012).

A visão de alguns estudiosos brasileiros, portanto, não se coaduna com a melhor compreensão acerca do consentimento informado na doação de gametas como será demonstrado. Com efeito, vedar a prática da doação compartilhada de forma peremptória é não considerar que a concepção de vida boa para muitas mulheres se perfaz pelo caminho da maternidade. Se esse caminho não pode ser trilhado pela via pública, diante da não alocação de recursos em RA, a mulher pode decidir, desde que adequadamente informada, por doar os seus oócitos e ter seu desejo de maternidade concretizado.

A situação de vulnerabilidade da doadora não lhe retira a autonomia quando promovida por equipe multidisciplinar de cuidados em saúde que assegure a essa mulher uma real compreensão do impacto e dos desdobramentos dessa escolha em sua saúde. Essas questões, contudo, tem sido ignoradas pela literatura brasileira que, partindo de situações abstratas, condena a prática da doação compartilhada sem averiguar a condição concreta das mulheres e os processos para a tomada de decisão, bem como sem propor diretrizes para que a prática seja desenvolvida em respeito aos direitos humanos da paciente. Assim, em seguida, tem-se o desiderato de tratar da vulnerabilidade da doadora de oócito. 


\section{A VULNERABILIDADE ACRESCIDA DA DOADORA DE OÓCITOS}

A noção de vulnerabilidade começou a ser difundida a partir de grupos feministas que, no início da década de 80 , se empenharam por substituir a ideia de agente independente, acentuada pelo liberalismo político, por uma concepção mais relacional da identidade que considerasse as necessidades das pessoas conforme suas vulnerabilidades específicas (PELLUCHON, 2016).

A autonomia tradicional, por partir de uma concepção extremamente individualista, ancora-se na visão do ser humano como autossuficiente e independente das relações intersubjetivas, cujos esforços estão inexoravelmente direcionados a maximizar seus ganhos pessoais. Em contraposição, a autonomia relacional, adotada pelos Direitos Humanos dos Pacientes, ao levar em conta a rede de conexões inerentes da vida humana, enfatiza que essas relações interferem necessariamente nas tomadas de decisões individuais.

Esse movimento de reconfiguração do conceito de autonomia, sem negá-la, propõe uma abordagem relacional tendo em vista que não há vida humana sem relação. 0 ser humano só conhece a si mesmo e só é capaz de definir-se em uma relação, com efeito a identidade é construída a partir do conjunto de relações travadas socialmente. 0 desenvolvimento da personalidade, a realização das potências humanas, em suma, a atualização de tudo aquilo que o ser humano pode ser e está chamado a ser, dá-se na relação com os outros (GONÇALVES, 2008). A intrínseca abertura relacional traz à luz a fragilidade do humano que, na relação inevitável com o outro, sempre estará vulnerável a sofrer danos, dessa forma, a autonomia relacional traz consigo a consciência do agir responsável para com o outro (HERRING, 2014). Nessa linha, a concepção de autonomia relacional conjuga-se com o reconhecimento da vulnerabilidade humana.

Toda a vida humana é permeada pela vulnerabilidade, como resultado das relações intersubjetivas humanas, da consciência da finitude e da fragilidade do corpo, sendo assim, uma condição ontológica da humanidade (HERRING, 2016). A vulnerabilidade ontológica, entretanto, não exclui o fato de que, em momentos particulares e determinados indivíduos 
experimentam vulnerabilidades específicas. Fatores como sexualidade, gênero, saúde, classe social, e outros, contribuem para distribuir distintamente experiências de vulnerabilidade.

No contexto das tecnologias reprodutivas, a doadora de oócito, foco deste artigo, busca por tratamentos para superar a infertilidade que, de acordo com a Organização Mundial da Saúde, define-se como a incapacidade de um casal engravidar após o período de 12 meses de relações sexuais regulares sem proteção contraceptiva. Sendo assim, sob a perspectiva da doadora de oócitos, sua vulnerabilidade é acrescida na medida em que se submete a riscos específicos no processo de estimulação ovariana sem se beneficiar diretamente do procedimento de RA. Ademais, ressalta-se a presença da assimetria da informação entre médico e a doadora e, por fim, em alguns casos, será possível identificar fatores socioeconômicos que agregam outro elemento na sua condição de vulnerabilidade acrescida, pois uma paciente com baixo poder aquisitivo tem um leque menor de escolhas no que diz respeito ao seu tratamento.

A identificação de distintos fatores que incrementam a vulnerabilidade é importante para auxiliar na identificação da resposta moral e jurídica mais apropriada. Desse modo, a resposta, a despeito do tom protetivo no sentido de minimizar os fatores assinalados, deve estar comprometida com o desenvolvimento de capacidades da paciente de modo a promover a agencia e a autonomia do indivíduo.

0 reconhecimento adequado da vulnerabilidade acrescida da doadora de oócitos é essencial para que os regramentos ético-jurídicos de RA levem em consideração tal aspecto e adote, conseguintemente, as medidas protetivas necessárias sem se descuidar da promoção de sua autonomia e agência. No caso da doação de oócito, a paciente doadora é simultaneamente vulnerável e autônoma, portanto, a promoção da sua autonomia dá-se a partir da garantia dos seus direitos à informação e à privacidade, pormenorizados nos tópicos seguintes. 


\section{O DIREITO À INFORMAÇÃO E O DIREITO À PRIVACIDADE DA DOADORA DE OÓCITOS}

Enquanto ramo do Direito Internacional dos Direitos Humanos, os Direitos Humanos dos Pacientes se constituem pelos direitos humanos constantes dos tratados que se aplicam ao contexto dos cuidados em saúde, (ALBUQUERQUE, 2016). Sendo assim, com base nos tratados e normas internacionais, bem como nas decisões dos órgãos de monitoramento dos direitos humanos da Organização das Nações Unidas - ONU e dos Sistemas Europeu, Interamericano e Africano de Direitos Humanos, pode-se inferir que o núcleo dos direitos humanos dos pacientes é formado pelo direito à vida; direito a não ser submetido à tortura nem a penas ou tratamentos cruéis, desumanos ou degradantes; direito ao respeito pela vida privada; direito à liberdade e à segurança pessoal; direito à informação; direito de não ser discriminado e direito à saúde (ALBUQUERQUE, 2016).

No presente artigo, enfatiza-se o direito à privacidade e à informação em razão de guardarem relação de pertinência temática com a problemática abordada neste estudo, qual seja a discussão em torno da moralidade da doação de gametas sob o enfoque da doadora, sua vulnerabilidade e direitos.

\section{DIREITO À INFORMAÇÃO}

0 direito à informação, invocado pela primeira vez pelo Conselho da Europa em 2009 com a adoção da Convenção sobre o Acesso a Documentos Oficiais, progressivamente, incorporou-se nos principais organismos internacionais como Comitê de Direitos Humanos da ONU, da Corte Europeia de Direitos Humanos, da Corte Interamericana de Direitos Humanos e do Comitê Europeu de Direitos Sociais.

A partir de uma extensa revisão da jurisprudência internacional dos direitos humanos, McDonagh (MCDONAGH, 2013) demonstra que em todos os organismos internacionais mencionados, o direito à informação é empregado sob uma perspectiva instrumental, ou seja, para dar sustentação a outros direitos tais como direito à vida, direito à privacidade, direitos econômicos e sociais, direito à liberdade de expressão, direito 
de participação política e direito ao devido processo legal. A perspectiva instrumental, entretanto, é restrita, pois o exercício do direito encontra-se condicionado ao direito que o fundamenta, o que inviabiliza sua utilização nas situações nas quais o demandante não apresenta nenhum direito a ser concretizado ou interesse específico para acessar a informação requisitada (MCDONAGH, 2013). Dessa forma, advoga-se por um direito à informação autônomo como pré-requisito para sociedades democráticas que se assentam primordialmente na transparência e na accountability governamental. Remove-se, assim, a necessidade de demonstrar a ligação da informação requisitada com a efetivação de outros direitos e torna-se ilimitado o acesso à informação independente da sua natureza.

0 direito autônomo à informação é particularmente desejável para cuidados em saúde, pois somente munido de informações adequadas sobre tratamentos, alternativas e efeitos adversos, o paciente estará apto a tomar uma decisão autônoma.

A informação configura pré-requisito essencial para que haja autonomia, sendo um direito do paciente e um dever do médico que é obrigado a empenhar esforços contínuos para transmitir ao paciente todos os aspectos envolvidos no procedimento o que, para além das questões técnicas, inclui também questões éticas, jurídicas e econômicas.

0 direito à informação, nos cuidados em saúde, tem como parâmetro o paciente. A informação deve ser ofertada de forma abrangente, transparente e isenta de viés, não devendo ser guiado quanto ao conteúdo e à extensão da informação pelo parâmetro do corpo médico, mas sim a partir da perspectiva do paciente (SPATZ; KRUMHOLZ; MOULTON,, 2016). Afasta-se, portanto, do paradigma do corpo médico como o padrão apropriado de cuidados razoáveis em saúde estabelecido pela Suprema Corte inglesa em 1957 no caso Bolam versus Friern Hospital Management Committee1. Esse caso retrata o paternalismo médico ao consagrar a avaliação do médico como parâmetro adequado para a informação em cuidados em saúde. A Suprema Corte inglesa também entendeu que a ausência de informação acerca de todos os riscos envolvidos não poderia ser considerada negligência se as informações fornecidas ao paciente estivessem em conformidade com os protocolos nacionais e internacionais. Esse posicionamento perdurou por mais de cinquenta anos sendo revertido 
apenas em 2015, no Caso Montgomery versus Lanarkshire Health Board no qual uma mulher diabética sofreu complicações obstétricas ao optar pelo parto normal que gerou redução severa da oxigenação no cérebro do feto. Esse problema, frequente em mulheres diabéticas que tem fetos maiores, ocorreu em razão da dificuldade de passagem do feto pelo canal vaginal. A paciente alegou que se soubesse do risco, teria optado por fazer uma cesárea. A médica obstetra, por sua vez, defendeu-se dizendo que não havia informado tal risco por ser a probabilidade de ocorrência pequena (SPATZ; KRUMHOLZ; MOULTON,, 2016).

A partir do caso narrado, a Suprema Corte Inglesa superou o posicionamento firmado no Caso Bolam, reconhecendo que a gestante deveria ter sido informada sobre todas as opções de cuidado de saúde bem como potenciais ricos e benefícios de cada um deles. Observa-se uma mudança de perspectiva, pois comunicação realizada pelo profissional de saúde deve tomar como parâmetro o paciente.

No contexto das técnicas de RA, um dos principais riscos a que se submetem as mulheres envolve a alta ingestão de hormônios que, a curto prazo, podem ocasionar a síndrome da hiperestimulação ovariana, a partir da qual podem se desenvolver vinte, trinta e até mais óvulos num só ciclo e os ovários crescem anormalmente, podendo torcer-se, o que exige cirurgia. Acrescenta-se, ainda, uma série de complicações potencialmente graves caracterizadas pela formação de múltiplos cistos ovarianos, associada ao aumento da permeabilidade capilar, que traz, como consequência, formação de ascite e hidrotórax, distúrbio hidroeletrolítico, hemoconcentração, distensão abdominal, náuseas, vômitos e diarreia. Nos casos mais severos, sobrevêm a hipovolemia, oligúria e fenômenos tromboembólicos. Isso significa que os vasos deixam passar líquido através de suas paredes, acumulando-se, esse líquido, na barriga, no tórax, podendo chegar à insuficiência dos rins, ao choque e até à morte (REIS, 2006).

No encontro da doadora de gametas com o profissional de saúde responsável pelo tratamento de infertilidade e a doação de oócitos, os efeitos a médio e longo prazos desses hormônios devem necessariamente ser informados e acompanhados, pois somente quando munida de informações suficientes e adequadas, a paciente poderá consentir ou não com as intervenções que serão realizadas em seu corpo. 


\section{DIREITO À PRIVACIDADE}

Sob a ótica do direito humano à privacidade, o paciente tem o direito de conduzir sua própria vida, concretizar juízos de valores e escolhas existenciais sem interferências e imposições. 0 Estado, enquanto garantidor dos direitos humanos, deverá zelar e adotar medidas legislativas e outras para assegurar tal direito.

No âmbito dos cuidados em saúde, essa abordagem traduz-se para o direito de recusar cuidados, o que engloba o direito de não realizar exames, testes ou procedimentos terapêuticos; direito de buscar outras opiniões médicas; direito de ter tempo suficiente para tomar decisões, salvo em situações de emergência e direito de ter suas diretivas antecipadas respeitadas pelos familiares e médicos (ALBUQUERQUE, 2016).

0 respeito pela vida privada também implica o direito de ter suas escolhas quanto à visita e ao exame do seu corpo observado pelos profissionais de saúde e, ainda, concede ao paciente total controle acerca dos seus dados sanitários. Assim, até mesmo o afastamento do seu direito à confidencialidade, em razão da proteção da saúde pública, de direitos e liberdades de terceiros ou da prevenção da ocorrência de crime, deve ser proporcional, mínimo e restrito ao alcance desses objetivos (ALBUQUERQUE, 2016).

Por fim, o direito ao respeito pela vida privada compreende igualmente o direito de consentir quanto a qualquer tipo de tratamento. O consentimento informado no campo dos direitos humanos sedimentase no Relatório do Relator Especial sobre Direito à Saúde, publicado em 2009, que o define como sendo uma decisão voluntária e suficientemente informada capaz de promover autodeterminação, integridade física e bem-estar do paciente (ALBUQUERQUE, 2016).

Desse modo, o consentimento informado é a concretização do respeito da autonomia do paciente para decidir sobre aquilo que lhes é mais íntimo: o corpo. Esse documento registra o encontro do paciente com o profissional de saúde; não se reduzindo a mera assinatura em um documento contendo informações técnicas de difícil compreensão, ao contrário, implica comunicação, diálogo franco com informações que 
sejam capazes de esclarecer o paciente acerca dos diferentes elementos envolvidos no seu tratamento.

Na nova era do consentimento informado, como salientado, reconhece-se a importância de que o processo de esclarecimento seja desenvolvido pela perspectiva do paciente e não do médico (SPATZ; KRUMHOLZ; MOULTON,, 2016). A decisão final será compartilhada, com atuação do profissional de saúde movido por uma lógica do cuidar (que não se confunde com paternalismo) e, concomitantemente, com a participação do paciente.

A participação da paciente na doação de oócitos e no direcionamento do seu tratamento, além de respeitar seu direito à privacidade, tem o condão de aumentar sua satisfação em relação ao tratamento escolhido e sua confiança no médico e no sistema em geral (EDOZIEN, 2016).

Os instrumentos utilizados para fins de consentimento dessa prática deverão, portanto, conter informações acessíveis e claras sobre todos os aspectos envolvidos. Tendo isso em vista, passa-se agora para a análise de três modelos de RA: o latino-americano, o britânico e o brasileiro.

\section{OS MODELOS DE RA SOB A ÓTICA DO DIREITO À PRIVACIDADE E À INFORMAÇÃO DA PACIENTE DOADORA DE OÓCITOS}

Com o objetivo de problematizar a incidência dos direitos à privacidade e à informação na doação de oócitos no Brasil, realizou-se uma comparação do modelo brasileiro normativo de RA com os modelos propostos pela REDLARA e pela Autoridade de Fertilização Humana e Embriologia do Reino Unido. Sendo assim, inicia-se pela análise dos formulários de consentimento informado apresentados pela REDLARA em 2011, cujo objetivo primordial da sua elaboração foi a unificação de critérios dos consentimentos de todos os centros de reprodução da América Latina, priorizando-se dois fatores: a quantidade de informação e a legibilidade.

Em relação às informações, todos os consentimentos informados formulados pela REDLARA apresentam uma estrutura básica que inclui o objetivo e a explicação da técnica, seus benefícios, riscos, desconfortos e 
efeitos secundários, alternativas ao tratamento, assim como alternativas em hipótese de fracasso, esclarecimento de que é possível modificar ou retirar o consentimento em algumas situações e espaços para preenchimento de informações personalizadas e contextualizadas às necessidades do paciente. No que tange à legibilidade, verifica-se um certo zelo quanto ao vocabulário e preferência por frases simples e breves.

Na elaboração dos documentos, três critérios foram utilizados: o critério da prática usual, reconhecido como necessário, mas insuficiente por não informar eventos graves e raros, como, por exemplo, o risco da síndrome da hiperestimulação ovariana; o critério do paciente médio, que impele informar vantagens e desvantagens da intervenção; e, por fim, o critério subjetivo, considerado o mais difícil, pois se busca a informação que o paciente não detém, mas deve saber para tomar a melhor decisão. Observa-se, neste critério, a adoção do parâmetro decidido, em 2015, no Caso Montgomery versus Lanarkshire Health Board.

O formulário do consentimento para doação de oócitos preconiza também o anonimato, de modo que a doadora não terá ciência sobre eventual gravidez da receptora, e estipula idade inferior a 36 anos para doar. Traz como benefício o estudo completo da fertilidade da doadora e como risco a hiperestimulação ovariana, a torção do ovário, a hipersensibilidade emocional pelo tratamento hormonal e espaço para preencher riscos personalizados. Há também menção a desconfortos como dor de cabeça, dor abdominal e mudança no estado de ânimo. A hipótese da doação compartilhada, contudo, não está prevista, havendo apenas alusão ao altruísmo das mulheres doadoras.

Em seguida, passa-se ao modelo de RA do Reino Unido, fiscalizado por um corpo regulatório específico, a HFEA, que em 1992, ao verificar a escassez da doação de oócitos, emitiu diretrizes permitindo a provisão de serviços voltados para tratamento de infertilidade em troca da doação de oócitos. Um dos argumentos empregados para corroborar a prática foi o fato de que as mulheres, por já estarem em tratamento, não seriam expostas a risco adicional, algo experimentado por doadoras não pacientes (BLYTH, 2002).

Em 1998, em consulta2 realizada pela HFEA acerca da doação compartilhada que questionava se essa prática deveria ser mantida, 
imediatamente extinta ou progressivamente afastada, constatou-se que a maioria dos entrevistados era contrária ao pagamento dos doadores de gametas, mas estava receptível à doação compartilhada, vista como a única alternativa para alguns(BLYTH, 2002). Na essência, existem duas mulheres compartilhando o mesmo problema de infertilidade. A partir das respostas e de intenso debate, a HFEA, em 2001 apresentou diretrizes permitindo a doação compartilhada, atualmente previstas na 8a edição do Código de Prática em reprodução assistida publicado em 2016 (HFEA, 2016a).

Há previsão de que o fornecimento insuficiente de oócitos pela doadora não compromete seu tratamento e que ela receberá aconselhamento personalizado e rotineiro antes, durante e após a doação (HFEA, 2016a) (HFEA, 2016b). Sendo assim, os centros deverão fornece à doadora aconselhamento adequado sobre as implicações da escolha, oportunidade para questionamentos e tempo de reflexão antes do consentimento para que esse seja verdadeiramente livre e sem precipitações. As clínicas também não poderão induzir ou completar qualquer manifestação de desejo (HFEA, 2016c).

Exige-se que a doadora tenha menos de 36 anos, que o acordo entre clínica e doadora preveja o número de ciclos de tratamento, o período de armazenamento, os procedimentos cobertos e que antes da autorização da paciente sejam fornecidas informações suficientes para correta compreensão da natureza, do propósito e das implicações da doação; informações sobre alternativas viáveis, expectativa de tempo para sucesso do tratamento, natureza dos riscos (imediatos e de longo prazo) para mulher e para a criança e ainda informações sobre o procedimento para modificar ou retirar o consentimento e sobre a importância de comunicar à clínica acerca de eventuais efeitos não esperados (HFEA, 2016a) (HFEA, 2016d). Doadora e receptora não terão ciência do resultado do tratamento da outra, o que é criticável por alguns autores que defendem ser essa decisão restrita à esfera de escolha das pacientes (BLYTH, 2002).

Não há nas diretrizes da HFEA a indicação de que o número de oócitos disponíveis pode afetar a qualidade do tratamento. Nesse sentido, Blyth (2002) considera que essa questão não deveria ser deixada no âmbito de escolha das clínicas, antes a HFEA, enquanto autoridade reguladora 
da matéria, deveria especificar um número mínimo de oócitos a serem disponibilizados tanto para o tratamento da doadora como para o da destinatária. Outras questões levantadas pelos entrevistados na consulta da HFEA, não abordadas nas diretrizes, dizem respeito à necessidade de garantir que as doadoras não sejam submetidas a regimes farmacológicos ou induções inapropriadas para maximizar a produção de oócitos.

No Brasil, não há propriamente um modelo, porquanto inexistem lei e órgão específico de fiscalização e regulação das práticas desenvolvidas no âmbito da RA, sendo urgente a implementação de controles adequados dos centros de RA. Na esteira, o controle realizado pela ANVISA restringese apenas às ações de fiscalização sanitária, não tem como foco os direitos dos pacientes.

A Resolução 2.121/15 traz em seu bojo a obrigatoriedade do consentimento livre e esclarecido informado para todos os pacientes submetidos às técnicas de RA. A Resolução determina que "os aspectos médicos envolvendo a totalidade das circunstâncias da aplicação de uma técnica de RA serão detalhadamente expostos, bem como os resultados obtidos naquela unidade de tratamento com a técnica proposta. As informações devem também atingir dados de caráter biológico, jurídico e ético". 0 preceito é abrangente, não define quais aspetos médicos deverão ser detalhados e como as informações serão transmitidas para os pacientes de modo a torna-las acessível.

Ainda, de acordo com a Resolução 2.121/15 “o documento de consentimento livre e esclarecido informado será elaborado em formulário especial e estará completo com a concordância, por escrito, obtida a partir de discussão bilateral entre as pessoas envolvidas nas técnicas de reprodução assistida". Não há, contudo, na normativa a previsão de quaisquer parâmetros para a elaboração do documento, o que acaba sendo feito conforme julgamento de cada clínica de RA.

A previsão da resolução do CFM exigindo um consentimento livre é de grande importância, contudo, genérica e insuficiente para proteger a paciente quando comparada à riqueza de detalhes presentes no modelo da REDLARA e no modelo britânico. A proteção é também frágil do ponto de vista formal, pois uma Resolução não estabelece direitos para os pacientes. Conclui-se, dessa forma, que no Brasil é premente que seja 
adotada uma lei de RA, bem como políticas, programas e protocolos nacionais, em consonância com o referencial dos Direitos Humanos dos Pacientes a fim de que os direitos à informação e à privacidade da doadora de gameta seja efetivado.

\section{CONSIDERAÇÕES FINAIS}

A doação de oócitos na modalidade compartilhada não deveria ser vedada em razão da possibilidade de ensejar o comércio de gametas, contudo, é imperioso que a prática seja balizada por lei elaborada com base na percepção da vulnerabilidade acrescida da doadora de gametas e do papel do Estado de resguardar seu direito à informação e à privacidade. Com efeito, o consentimento informado no caso ora abordado é crucial para se assegurar que a doadora está ciente dos eventos adversos provenientes do procedimento, inclusive a repercussão que poderão ter para sua vida cotidiana. Reconhece-se que no âmbito da doação de oócitos, a decisão é complexa e para que a paciente-doadora emita um juízo próprio, fazse imprescindível o conhecimento integral sobre o objeto e sobre as implicações da decisão. Conclui-se que a Resolução do CFM não é suficiente para se regular a prática no Brasil, há que se incorporar os direitos da paciente doadora de oócitos em lei específica, de modo que se preveja o processo de tomada de decisão com apoio de equipe multidisciplinar e manejo de informação completa, acessível e clara sobre os riscos e benefícios envolvidos nesse procedimento.

\section{NOTAS}

1 O Sr. Bolam era paciente voluntário no Hospital Friern, instituição especializada em saúde mental, e aceitou receber terapia eletro-convulsiva. Entretanto, durante o procedimento, acabou não recebendo relaxante muscular e seu corpo não estava contido o que lhe causou danos sérios, incluindo fraturas no acetábulo. Em razão disso, processou o hospital e requereu compensação financeira alegando negligência médica pela ausência de medicação de relaxantes, de contenção do seu corpo e de informações sobre os riscos envolvidos.

2 A consulta abarcou respostas de pacientes que receberam ou não tratamento usando gametas doados, profissionais das clínicas de infertilidade e outros voltados para cuidados em saúde em geral, associações dos profissionais de saúde, grupos de apoio ao paciente e outras pessoas que manifestaram o interesse em contribuir. 


\section{REFERÊNCIAS}

ALBUQUERQUE, Aline. Direitos Humanos dos Pacientes. Curitiba: Juruá 2016.

BRASIL, Resolução no 2.121 do Conselho Federal de Medicina de 16 de julho de 2015. Adota as normas éticas para a utilização das técnicas de reprodução assistida, anexas à presente resolução, como dispositivo deontológico a ser seguido pelos médicos e revoga a Resolução CFM no 2.013/13. Diário Oficial [da] República Federativa do Brasil, Brasília, DF, 24 set. 2015. Disponível em: <http://www.portalmedico.org.br/resolucoes/CFM/2013/2013_2013.pdf.> Acesso em 12 de ago. 2013.

BLYTH, E. Subsidized IVF: the development of "egg sharing" in the United Kingdom. Human reproduction (Oxford, England), v. 17, n. 12, p. 3254-9, 2002. Disponível em: <http://www.ncbi.nlm.nih.gov/pubmed/12456633>.

CORRÊA, Marilena V. Novas tecnologias reprodutivas : doação de óvulos . 0 que pode ser novo nesse campo ? Cadernos de Saúde Pública, v. 16, n. 3, p. 863-870, 2000.

CORRÊA, Marilena C D V; LOYOLA, Maria Andrea. Tecnologias de reprodução assistida no Brasil: opções para ampliar o acesso. Physis, v. 25, n. 3, p. 753-777, 2015.

EDOZIEN, Leroy C. Self-determination in health care: a property approach to the protection of pacients's right. New York: Routledge, 2016.

ES, Spatz; HM, Krumholz; BW, Moulton. The new era of informed consent: Getting to a reasonable-patient standard through shared decision making. Jama, p. 6-7, 2016.

GONÇALVES, Diogo Costa. Pessoa e direitos de personalidade : fundamentação ontológica da tutela. Coimbra: Almedina, 2008.

GÜRTIN, Zeynep B.; AHUJA, Kamal K.; GOLOMBOK, Susan. Egg-sharing, consent and exploitation: Examining donors' and recipients' circumstances and retrospective reflections. Reproductive BioMedicine Online, v. 24, n. 7, p. 698-708, 2012.

HERRING, Jonathan. Relational Autonomy and Family Law. Cham: Springer International Publishing, 2014.

HERRING, Jonathan. Vulnerable Adults and the Law. United Kingdom: Oxford: University Press, 2016. 
LEVINE, Aaron D. Self-regulation, compensation, and the ethical recruitment of oocyte donors. The Hastings Center report, v. 40, n. 2, p. 25-36, 2010.

MCDONAGH, Maeve. The Right to Information in International Human Rights Law. Human Rights Law Review, v. 13, p. 25-55, 2013.

PARAMES, Suelen Fernanda et al. What influences oocyte donation when there is no financial compensation? Reprodução \& Climatério, v. 29, n. 1, p. 8-12, 2014.

PELLUCHON, Corine. Taking vulnerability seriously: what does it change for Bioethics and politics? In: MASFERRER, A; GARCÍA-SÁNCHEZ, E (Org.). Human Dignity of the Vulnerable in the Age of Rights: Interdisciplinary Perspectives. Switizerland: Springer International Publishing, 2016. p. 293-312.

REIS, Ana Regina Gomes. 0 ethos em tempo de Bioética: o site como tropo. In: FERREIRA, VERÔNICA; ÁVILA, MARIA BETÂNIA; PORTELLA, ANA PAULA (Org.).

. Feminismo e novas Tecnologias Reprodutivas. Recife: SOS CORPO - Instituto Feminista para a Democracia, 2006. p. 79-94.

SANDI, Stella de Faro. Reflexões sobre a doação compartilhada de óvulos no Brasil. Diversitates, v. 4, n. 2, p. 66-83, 2012.

THE HUMAN FERTILISATION AND EMBRYOLOGY AUTHORITY. Counselling. Code of Practice. 8. ed. London: Spring Gardens, 2016a. .

THE HUMAN FERTILISATION AND EMBRYOLOGY AUTHORITY. Egg Sharing Arrangements. Code of Practice. 8. ed. London: Spring Gardens, 2016b. .

THE HUMAN FERTILIZATION AND EMBRIOLOGY AUTHORITY. Consent to treatment, storage, donation, training and disclosure of information. Code of Practice. 8. ed. London: Spring Gardens, 2016c.

THE HUMAN FERTILIZATION AND EMBRIOLOGY AUTHORITY. Information to be provided prior to consent. Code of Practice. 8. ed. London: Spring Gardens, 2016d.

Recebido em: 22-12-2017

Aprovado em: 26-10-2020

\section{Kalline Carvalho Gonçalves Eler}

Doutora em Bioética e Direitos Humanos pela Universidade de Brasília. Mestra em Direito pela Universidade Federal de Juiz de Fora. Graduação em Direito. Professora Assistente da Universidade Federal de Juiz de Fora

- Campus Governador Valadares. Possui linhas de pesquisa na área de 
Direito Civil e Direitos Humanos com ênfase em: Pessoa, Personalidade e Capacidade Jurídica, Paternidade e Maternidade, Direitos do Paciente. E-mail: kallinecarvalho@hotmail.com

\section{Aline Albuquerque Sant'Anna de Oliveira}

Pós-Doutorado em Direitos Humanos e Pesquisadora Visitante do Centro de Direitos Humanos da Universidade de Essex, Inglaterra - Bolsa de Estágio PósDoutoral da Capes (2014/2015). Pós-Doutorado em Direito Humano à Saúde e Pesquisadora Visitante no Instituto de Direitos Humanos da Universidade de Emory, Estados Unidos (2011). ). Mestrado em Direito pela pela Universidade do Estado do Rio de Janeiro (1997). Pesquisadora Visitante no Instituto Bonavero de Direitos Humanos da Universidade de Oxford (2018). Professora Credenciada da Pós-Graduação em Bioética da Universidade de Brasília. Diretora do Instituto Brasileiro de Direito do Paciente. Professora Convidada da Faculdade de Saúde Pública da USP. Professora do Mestrado em Políticas de Saúde da FIOCRUZ. Advogada da União. Autora dos livros: Capacidade Jurídica e Direitos Humanos; Curso de Direitos Humanos; Direitos Humanos dos Pacientes; e Bioética e Direitos Humanos. Doutorado em Ciências da Saúde, Área de Concentração Bioética pela Universidade de Brasília e Universidade de Zurique - Bolsa Doutorado Sanduíche da Capes (2010). Chefe da Assessoria Jurídica da Secretaria de Direitos Humanos da Presidência da República (2015/2016). Chefe da Coordenação de Legislação e Normas do Ministério da Saúde (2007-2010). Especialista em Saúde Internacional pela OPAS/OMS (2014) e em Bioética pela Cátedra UNESCO de Bioética da Universidade de Brasília (2004). Professora do Curso de Especialização em Bioética da Cátedra UNESCO de Bioética. Professora Associada do Programa de Mestrado e Doutorado do UniCEUB. Membro do CBEC. Professora de Direitos Humanos da Pós-Graduação do UniCEUB. Professora do Curso de Especialização em Direito Médico da UERJ, do Curso de Especialização em Direito Sanitário da FIOCRUZ. Professora de Direitos Humanos da Pós-Graduação do UniCEUB. Pesquisadora Associada do Núcleo de Diplomacia e Saúde da FIOCRUZ. Coordenadora da Clinica de Direitos Humanos do UniCEUB. Coordenadora-Geral do Observatório de Bioética e Direitos Humanos do Paciente do PPGBioética e Cátedra UNESCO de Bioética da UnB. Membro do Comitê de Bioética do Grupo Hospitalar Conceição. Membro do Comitê de Bioética do Hospital de Apoio do DF. Conselheira do Conselho Nacional de Saúde (2013/2015).Membro da RedLatinoamericana e do Caribe de Bioética da UNESCO. Membro do Conselho Científico da Sociedade Brasileira de Bioética (2013/2015). Membro do Comitê de Ética em Pesquisa do UniCEUB. E-mail: alineaoliveira@hotmail.com

Universidade de Brasília - Campus Darcy Ribeiro

Brasília, DF, 70910-900 
